\title{
Seqüências de (sibilante + consoante) no português de Belo Horizonte
}

\author{
Thaïs Cristófaro-Silva \\ Universidade Federal de Minas Gerais \\ $\mathrm{KCL}$ \\ Daniela Mara Lima Oliveira \\ Universidade Federal de Minas Gerais
}

\section{Abstract}

This paper investigates cases of sound variation involving sequences of (sibilant + consonant) in Brazilian Portuguese (BP). Emphasis is given to the analysis of alveolar (sibilant + stop) sequences as in the word - festa [ $f \varepsilon$ sta] - and to the alveopalatal (sibilant + affricate) sequences - as in the word triste ['tri $t \mathrm{t} i \mathrm{i}$. The cases of variation we will be dealing with involve the loss of the stop or the affricate where only the sibilant is manifested: festa 'party '[ ' f $\varepsilon$ sta] à [' $\mathrm{f} \varepsilon \mathrm{sa}$ ]

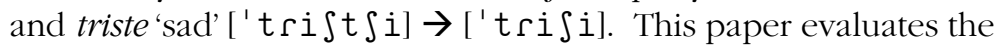
role of phonetic properties as potential motivation for the variation: agreement of place of articulation and also agreement of voicing 
for the consonants in the sequence is considered. The fact that the sequences involved in the variation are related to a complex syllable pattern - that is, (coda-onset) - will also be explored. Some structural aspects which may condition the phenomena will be addressed: stress placement and the quality of the vowel which precedes the (coda-onset) sequence. It will be suggested that the lack of conditioning structural factors leads us to evaluate this case of variation within the Lexical Diffusion model (WANG, 1969). Lexical Diffusion appears to be the most appropriate approach to analyse the phenomena addressed in this paper, since it accounts for the different behaviour of some structurally similar sequences. Finally, the paper indicates some aspects to be pursued in future research. 


\section{INTRODUÇÃO}

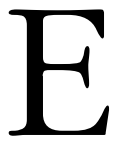

ste trabalho explora casos de variação sonora em seqüências de (sibilante + consoante) no português brasileiro. A ênfase será dada às seqüências de (sibilante + oclusiva) alveolares como na palavra festa [' $f \varepsilon s t a]$ - e às seqüências de (sibilante + africada) alveopalatais - como na palavra triste['t $\left.r i \int t \int i\right]$. A variação que pretendemos avaliar relaciona-se aos casos em que a consoante oclusiva ou africada é cancelada e somente uma sibilante ocorre: festa

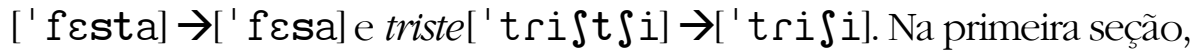
apresentamos o problema a ser investigado, mostrando que o fenômeno ocorre também em outras línguas. Na segunda seção, avaliamos aspectos fonéticos dos segmentos envolvidos na expectativa de encontrarmos a motivação para tal fenômeno. Na terceira seção, investigamos o papel da estrutura silábica. Na quarta seção, consideramos em detalhes os casos de variação em que uma sibilante ocorre seguida da consoante africada, como em ginást ica. Nesses casos podemos observar a variação em pelo menos três aspectos: a) uma sibilante alveolar é seguida da africada: [3i ' nast $\left.\left.\int i k a\right], b\right)$ uma sibilante alveopalatal é seguida da africada: [3i 'na $\mathrm{t} \int \mathrm{ika}$ ] e c) uma sibilante alveopalatal ocorre e a africada é cancelada: [3i 'na $i k a]$. Esses casos de variação serão avaliados em relação ao acento tônico e à vogal precedente. O papel de itens léxicos específicos também é considerado. Os dados são do português de Belo Horizonte, mas o fenômeno em questão foi observado também entre falantes de outras variedades do português brasileiro. Finalmente, indicam-se aspectos a serem abordados em pesquisas futuras. 


\section{AVALIAÇÃO DO PROBLEMA}

Tem sido observado na literatura que pode ocorrer o cancelamento da oclusiva em uma seqüência de (sibilante+oclusiva) alveolares. Em (1) temos exemplos desse fenômeno. Os sons que estamos investigando aparecem em negrito e estão sublinhados nos exemplos que se seguem.

(1) a. Checo (BARRY \& ANDREEVA, 2001) de uma distância [vevzda:losti] [fvezda:losi]

b. Italiano (BARRY \& ANDREEVA, 2001) dentista [dentista] [dentisa]

c. Português brasileiro (CRISTÓFARO-SILVA, 2000) festa [festa] [fesa]

Os dados em (1) demonstram que, quando uma sibilante alveolar desvozeada ocorre em posição posvocálica e é seguida por uma consoante oclusiva alveolar desvozeada, pode acontecer a simplificação e somente a sibilante ocorre. Ou seja, uma seqüência segmental do tipo [st] pode ocorrer como [s]. Nos exemplos apresentados em (1), temos formas alternantes, isto é, as duas formas ocorrem em competição nessas línguas. Contudo, em uma língua como o inglês, atestamos casos em que a redução de [st] para [s] ocorreu em algumas palavras e, atualmente, não há competição (ocorre somente a forma com a sibilante): castle [ka : sl] ou listen [l Isn]. Isso implica que o fenômeno em questão pode ter um caráter alternante que, eventualmente, pode se tornar categórico. Por outro lado, seqüências segmentais do tipo [st] ocorrem no inglês atualmente, sem sofrerem a redução para apenas sibilante: pasta 'macarrão' [pæst ə], vest 'corpete' [vest], street 'rua' [stri : t]. Note que a seqüência segmental em questão [st] comporta-se de maneira diferente em cada grupo de palavras. Nas palavras castle e listen, a seqüência [st] foi reduzida a [s] e, nas palavras pasta, vest e street, a seqüência [st] foi preservada. Podemos dizer que um determinado fenômeno pode afetar um grupo de palavras em um determinado 
estágio (como as palavras castle, listen), mas não afetar um outro grupo (como as palavras pasta, vest, street). Nós retomaremos esse ponto ao final deste artigo, quando avaliamos o comportamento diferenciado de seqüências estruturalmente semelhantes.

Duas propostas podem ser sugeridas para explicar casos de variação e mudança sonora: neogramática e difusionista. A proposta neogramática assume que as mudanças sonoras são regulares, foneticamente graduais e lexicalmente abruptas. A proposta difusionista assume que as mudanças sonoras não são necessariamente regulares, são foneticamente abruptas e lexicalmente graduais. Este trabalho pretende investigar qual dessas propostas seria mais apropriada para explicar o fenômeno de redução das seqüências de (sibilante + oclusiva) alveolares e de (sibilante + africada) alveopalatais para somente sibilante.

O português de Belo Horizonte apresenta casos semelhantes aos ilustrados em (1). Alguns exemplos são ilustrados em (2) e os sons em questão encontram-se em negrito e sublinhados:
a. festa
['festə]
[ $f \varepsilon s \ominus]$
b. costas
['kostəs]
['kosəs]
c. pasta
['paste]
['pasə]
d. agosto
[a'gostu]
[a' gosu]

Uma análise dos casos ilustrados em (2) - que envolvem uma seqüência de (sibilante + oclusiva) alveolares - é apresentada em Cristófaro-Silva (2000, 2001b). Um caso adicional apontado em Cristófaro-Silva (em preparação) relaciona-se às seqüências de (sibilante + africada) alveopalatais. Alguns exemplos são apresentados em (3) e os sons em questão encontram-se em negrito e sublinhados:

(3)
a. triste
['tristsi]
['trisi]
b. vestido
[vis'tsidu]
[vi ' $\operatorname{idv]}$
c. desde
['dezd3I]
['dezI]
d. jurisdição
[3urizdzi 'sãun]
[3urizi 'sãun]

O fenômeno ilustrado em (3) expressa que, em seqüências de (sibilante + africada) alveopalatais, pode haver variação e somente 
a sibilante ocorrer. Esse fenômeno é também observado em limite de palavras. Alguns exemplos são apresentados em (4).
(4)
a. meus tios
[meus 'tsius]
[mev 'Sius]
b. dois tipos
['doIs 'tsipus]
[dor ' Sipus]
c. Juiz de Fora
[zuizdzi forə]
[3uizi'forə]
d. giz de cera
[3izdzi'serə]
[3izi' 'serə]

Os casos ilustrados em $(3,4)$ ocorrem somente em variedades do português brasileiro em que as oclusivas alveolares são palatalizadas e, neste caso, temos [' t $\left.\int i a\right]$ e ['dzia], enquanto em variedades que não apresentam a palatalização de oclusivas temos [' tia] e ['dia]. Os casos ilustrados em $(3,4)$ devem, portanto, ser avaliados juntamente com o fenômeno de palatalização. Isso será feito posteriormente. Neste estágio gostaríamos de generalizar afirmando que, em seqüências de (sibilante + oclusiva) alveolares e (sibilante + africada) alveopalatais, pode haver variação e somente a sibilante ocorrer.

Como ocorre com freqüência em casos de variação e mudança sonora, podemos sugerir que a motivação para tal fenômeno seja a semelhança fonética: as consoantes sibilantes e obstruintes compartilham o mesmo ponto de articulação (alveolar ou alveopalatal) e o mesmo grau de vozeamento (vozeado ou desvozeado). Há diferença quanto ao grau e à natureza da estritura das consoantes em seqüência: uma das consoantes é uma fricativa sibilante e a outra é uma oclusiva ou africada. As consoantes oclusivas e africadas podem ser agrupadas como consoantes obstruintes. Posteriormente, avaliaremos o comportamento das demais consoantes obstruintes do português quando seguidas de sibilantes.

Vale ressaltar ainda que o caso em questão envolve seqüências sonoras que ocorrem em uma estrutura silábica complexa, em que a sibilante aparece na posição posvocálica (de coda) e a oclusiva ou a africada ocorre no início da sílaba na posição de onset. Portanto, a complexidade silábica e a semelhança fonética podem ser vistas como fatores favorecedores para que ocorra o cancelamento de uma das consoantes. 
Temos dois aspectos a serem investigados. O primeiro deles está relacionado ao comportamento de seqüências de (sibilante + consoante) de maneira geral no português. Pretendemos demonstrar que as seqüências (sibilante + oclusiva) alveolares e (sibilante + africada) alveopalatais comportam-se de maneira distinta de outras seqüências de (sibilante + consoante) em português. O segundo aspecto a ser investigado é a motivação para o fenômeno. Nas próximas páginas, exploraremos o papel desempenhado pela semelhança fonética e pela estrutura silábica. Finalmente, avaliaremos como esse fenômeno está sendo implementado lexicalmente.

\section{A SEMELHANÇA FONÉTICA}

Vimos na seção anterior que as seqüências de (sibilante + oclusiva) e (sibilante + africada) que são reduzidas a uma sibilante devem concordar quanto ao ponto de articulação e quanto ao grau de vozeamento. Essa observação nos leva a sugerir que há motivação fonética para o fenômeno. Os dois requisitos devem ser satisfeitos: concordância quanto ao ponto de articulação e quanto ao grau vozeamento. Para corroborar essa hipótese, devemos investigar outras seqüências de (sibilante + consoante) em português. Os exemplos em (5) ilustram casos em que uma sibilante é seguida de uma consoante alveolar no português. Ou seja, as consoantes adjacentes concordam quanto ao ponto de articulação e quanto ao vozeamento.

asno

[ 'aznu ]

Islamismo

[izla ' mizmu]

${ }^{\circ}\left[{ }^{\prime} \mathrm{azv}\right]$

*[iza ' mizmu]
[ 'afinu ]

[ifila ' mizmu]

Os asteriscos indicam que somente a ocorrência da sibilante não é possível nesses casos ( $3^{\underline{a}}$ coluna). Contudo, alternativamente, pode ocorrer o enfraquecimento da sibilante e esta se manifestar como uma fricativa glotal. Esse fenômeno é indicado na coluna mais a direita em (5).

Observe que, nos casos de (5), temos a articulação alveolar das duas consoantes, e ocorre um fenômeno diferente dos fenômenos considerados em $(2,3,4)$. No caso de $(5)$, pode ocorrer o enfraquecimento 
do s-posvocálico para [h] e, nos casos de $(2,3,4)$, pode ocorrer o cancelamento da oclusiva ou africada em seqüências de (sibilante + oclusiva) alveolares e (sibilante + africada) alveopalatais. Se o cancelamento da oclusiva ou africada em $(2,3,4)$ fosse motivado exclusivamente pela concordância quanto ao ponto de articulação e quanto ao vozeamento das consoantes envolvidas, esperaríamos que em outras seqüências de consoantes que compartilhem o mesmo ponto de articulação e vozeamento - como em $(3,4)$ - o mesmo fenômeno ocorresse. Esse não é o caso. Podemos concluir que, além da semelhança quanto ao ponto de articulação e vozeamento, é essencial que tenhamos (sibilante + oclusiva) alveolares ou (sibilante + africada) alveopalatais. Os fatos apresentados em $(2,3,4,5)$ mostram também que seqüências estruturalmente semelhantes, ou seja, (sibilante + consoante) podem ter comportamentos diferentes.

Considere os exemplos em (6) que ilustram as demais seqüências de (sibilante + consoante) no português.

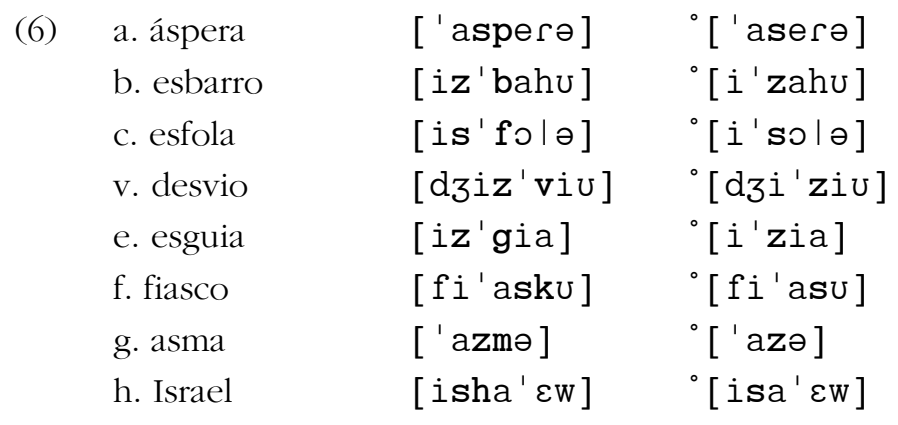

Os dados em (6) mostram que nesses casos não ocorre o cancelamento da consoante que segue a sibilante. Isso é indicado nas formas com asteriscos (coluna da direita). Quando ocorre variação nos exemplos de (6), temos o enfraquecimento da sibilante como uma fricativa glotal: desvio[dziz 'viv] alterna com [dzih 'viv]. Como foi mencionado anteriormente, os casos de enfraquecimento da sibilante em posição posvocálica merecem ainda uma investigação detalhada em português.

Uma outra observação interessante nos exemplos de (6) é que (6a-f) compreendem consoantes obstruintes. As consoantes 
[t , d, t $\left.\int, d 3\right]$ também são consoantes obstruintes. Contudo, quando estas últimas consoantes são precedidas de sibilante, o comportamento é diferente dos casos de (sibilante + obstruinte) ilustrados em (6a-f). Em (6a-f) a sibilante permanece ou é enfraquecida para uma fricativa glotal: desvio[dziz'viv] ou [dzih'viv]. Nos casos em que uma sibilante é seguida de [t, d, t $\left.\int, d z\right]$, a obstruinte é cancelada e a sibilante permanece: festa [' fEstə] ou [' fEsə] e desde['dezdzI] ou ['dezI]. Novamente, verificamos que seqüências estruturalmente semelhantes, ou seja, (sibilante + consoante) podem ter comportamentos diferentes (compare os dados:2,3,4,5,6).

Como generalização, podemos afirmar que, em seqüências do tipo (sibilante + oclusiva) alveolares e (sibilante + africada) alveopalatais, a oclusiva e a africada podem ser reduzidas a uma sibilante. A natureza da estritura também desempenha um papel importante. As consoantes em seqüência devem ser (sibilante + oclusiva) alveolares ou (sibilante + africada) alveopalatais, observandose a concordância do lugar de articulação e do vozeamento.

Embora possamos postular que parâmetros fonéticos sejam motivadores para o fenômeno que estamos analisando, devemos observar que, de fato, ocorre o cancelamento de uma consoante (a obstruinte). Certamente, há semelhança fonética na seqüência a ser alterada - sibilante seguida de [t, d, t $\int, d_{3}$ ] - mas a semelhança fonética não pode sozinha ser o fator motivador para o cancelamento da consoante oclusiva. Vamos sugerir que a simplificação das seqüências de sibilante seguida de [t, $\mathrm{d}, \mathrm{t} \int \mathrm{d}, \mathrm{d} 3$ ] para sibilante procede como decorrência da compressão e redução de esforço articulatório (BROWMAN \& GOLDSTEIN,1992). Um fato importante que segue a hipótese de compressão e redução de esforço articulatório é que estruturas silábicas complexas tendem a ser alteradas. Esta hipótese - de compressão e redução de esforço articulatório em estruturas silábicas complexas - será considerada em detalhes em trabalho futuro (OLIVEIRA, em preparação). O papel da estrutura silábica no fenômeno que estamos investigando será considerado na seção seguinte. 


\section{A ESTRUTURA SILÁBICA}

Esta seção considera o papel da estrutura silábica como fator motivador do fenômeno que estamos analisando. O padrão silábico CV (consoante seguida de vogal) é recorrente em todas as línguas naturais e é, portanto, visto como um padrão silábico universal e nãomarcado. Línguas que apresentam um único padrão silábico têm a sílaba CV. Outros padrões silábicos ocorrem em algumas línguas e não em outras e podem existir relações tipológicas entre padrões silábicos: por exemplo, línguas que têm o padrão silábico CCV, como em prato, também têm o padrão silábico CVC, como em larga. O que nos interessa aqui é que o fenômeno investigado apresenta um padrão silábico marcado em que uma consoante posvocálica é seguida de outra consoante na sílaba seguinte. O diagrama que se segue ilustra a representação da palavra festa [' f $\varepsilon$ stə] assumido pela Fonologia Autosegmental (GOLDSMITH, 1990).

\begin{tabular}{|c|c|c|c|}
\hline & $\delta$ & & $\delta$ \\
\hline / & 1 & & 11 \\
\hline $\mathrm{O}$ & $\mathrm{R}$ & $\mathrm{O}$ & $\mathrm{R}$ \\
\hline & $\Lambda$ & 1 & 1 \\
\hline 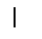 & $\mathrm{N}$ & C I & I \\
\hline | & I & 11 & | \\
\hline $\mathrm{x}$ & $\mathrm{x}$ & $\mathbf{x}$ & $\mathrm{x}$ \\
\hline & 1 & 11 & \\
\hline & $\varepsilon$ & & \\
\hline
\end{tabular}

$\mathrm{Na}$ representação (7), N se refere ao núcleo, O se refere ao onset, $\mathrm{R}$ se refere à rima e $\mathrm{C}$ se refere à coda. $\mathrm{O}$ símbolo $\delta$ se refere ao nódulo da sílaba. Um dos desenvolvimentos importantes da Fonologia Autosegmental foi o estabelecimento de uma relação formal entre um onset e a coda da sílaba precedente. Nesse contexto ocorrem vários fenômenos fonológicos em várias línguas. Exemplos são a assimilação sistemática de vozeamento ou a perda da consoante nasal em coda e a nasalização da vogal que a precede. Um outro fenômeno que ocorre entre (coda + onset) é o cancelamento da consoante em coda. Os exemplos em (8) ilustram casos do português brasileiro em que uma consoante em coda é cancelada: 
(8) a. Cancelamento de nasal em coda (MATTOSO CÂMARA, 1970)

$$
\begin{array}{ll}
\text { campo } & \text { ['kãpu] } \\
\text { anda } & \text { ['ãdə] }
\end{array}
$$

\begin{tabular}{|c|c|}
\hline porque & [puh 'ke] \\
\hline & ['mah $\left.\int ə\right]$ \\
\hline
\end{tabular}

b. Cancelamento de 'r' em coda (OLIVEIRA, 1981)

Contudo, há casos em que a consoante em coda pode permanecer. Os casos em (9) ilustram essa possibilidade. Em (9a) a nasal em coda permanece e a oclusiva que a segue é cancelada. Em (9b) o 'r' em coda permanece e a oclusiva que o segue é cancelada.

\begin{tabular}{|c|c|}
\hline comendo & [ku 'mẽdv ] \\
\hline rindo & ['hĩdv ] \\
\hline
\end{tabular}

a. Cancelamento do 'd ' pós-nasal (MOLLICA, 1998)

b. Cancelamento do ' $g$ ' precedido por R posvocálico (CRISTÓFAROSILVA, 2000)

$$
\begin{array}{lll}
\text { pergunta } & \text { [peh' 'gũtə] } & \text { [pe'hũtə] } \\
\text { perguntei } & \text { [pehgũ'teI }] & \text { [pehũ'teI }]
\end{array}
$$

Generalizando, podemos afirmar que seqüências consonantais de (coda + onset) são estruturas instáveis e podem sofrer alterações. Como estratégia de simplificação de uma estrutura silábica marcada, ou seja, (coda + onset) tanto a consoante em coda quanto a consoante em onset podem ser canceladas. Para uma melhor compreensão do fenômeno estudado, sugerimos que o cancelamento de consoantes nesse tipo de estrutura silábica complexa, ou seja, (coda + onset) pode seguir os padrões silábicos recorrentes na língua em questão. Essa hipótese será investigada em trabalho futuro (OLIVEIRA, em preparação).

Como conclusão da investigação sobre a semelhança fonética e a estrutura silábica, podemos afirmar que esses dois fatores, possivelmente, favorecem e contribuem para a variação atestada nas seqüências sonoras que estamos investigando. Isto porque as seqüências sonoras em questão encontram-se em estruturas silábicas complexas e há semelhança fonética entre os segmentos envolvidos. A hipótese de compressão e redução do esforço articulatório em 
estruturas silábicas complexas (BROWMAN \& GOLDSTEIN, 1992) será investigada com o objetivo de fornecer uma explicação mais abrangente para o fenômeno em análise.

No restante deste artigo, avaliaremos, em maiores detalhes, os casos em que uma sibilante alveopalatal segue uma africada alveopalatal: triste ['tri $\left.\int t \int i\right]$. Restringiremos a análise aos casos em que as duas consoantes são desvozeadas: [ $\int \mathrm{t} \int$ ]. Isto porque os casos de seqüências vozeadas do tipo [3dz] são pouco freqüentes no português (cf. nota 2). Considerando-se o número reduzido de palavras com seqüências do tipo [3d3], não poderíamos investigar a distribuição estrutural dessas seqüências em relação ao padrão acentual (se a seqüência ocorre em sílaba tônica ou átona) e nem quanto à vogal precedente. Na próxima seção, consideraremos as seqüências de (sibilante + africada) alveopalatais desvozeadas em português.

\section{SEQÜÊNCIAS DE (SIBILANTE + AFRICADA) ALVEOPALATAIS}

Nesta seção investigamos seqüências segmentais do tipo [ $\left.t \int\right]$ que passam a se manifestar como [S]. Restringimo-nos aos segmentos desvozeados por razões distribucionais (cf. nota 2). Faz-se pertinente, portanto, considerarmos a distribuição da consoante [S] na estrutura silábica do português.

A sibilante alveopalatal [S] ocorre em todas as variedades do português em posição inicial de sílaba (em início ou meio de palavra). Os exemplos em (10) ilustram estes casos:

(10) Distribuição das sibilantes alveopalatais em início de sílaba:

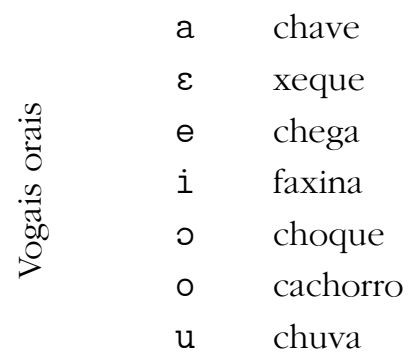




\begin{tabular}{|c|c|c|}
\hline & ã & chance \\
\hline 践 & $\tilde{e}$ & enchente \\
\hline 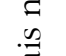 & $\tilde{I}$ & chimpanzé \\
\hline $\begin{array}{l}0 \\
0 \\
0\end{array}$ & Õ & rechonchudo \\
\hline & $\tilde{\mathrm{u}}$ & chumbo \\
\hline s & OI & choio \\
\hline & eU & encheu \\
\hline$\stackrel{\mathscr{n}}{\circ}$ & ãU్ & chão \\
\hline
\end{tabular}

As sibilantes alveopalatais também ocorrem em final de sílaba no português brasileiro e nesse contexto marcam variação dialetal. $\mathrm{Na}$ variedade carioca, uma sibilante alveopalatal ocorre, sistematicamente, em final de sílaba. Na variedade paulista, as sibilantes alveolares ocorrem, sistematicamente, em final de sílaba. Já na variedade de Natal, as sibilantes alveopalatais ocorrem seguidas de consoantes alveolares. Finalmente, na variedade mineira de Belo Horizonte, ocorre a sibilante alveolar, exceto quando uma africada alveopalatal ocorre no início da sílaba seguinte. Estes fatos são ilustrados em (11).

(11) Sibilantes em final de sílaba

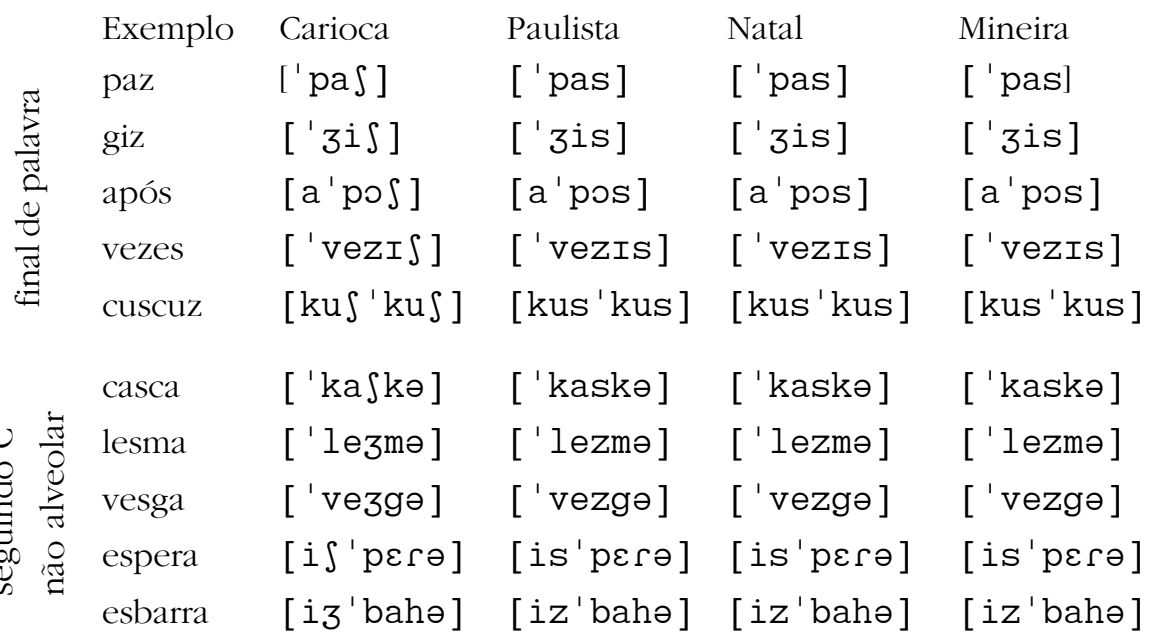




\begin{tabular}{|c|c|c|c|c|c|}
\hline \multirow{5}{*}{. } & Exemplo & Carioca & Paulista & Natal & Mineira \\
\hline & asno & ['aznu ] & ['aznu ] & ['aznu ] & [ 'aznv ] \\
\hline & islamismo & [izlã 'mizmv ] & [izlã 'mizmu] & [izlã'mizmu ] & [izlã'mizmu ] \\
\hline & estudo & [is'tudv ] & [is'tudv ] & [is'tudv ] & [is'tudu ] \\
\hline & festa & ['f $\left.\varepsilon \int t ə\right]$ & [ 'festə] & ['festə] & ['festə] \\
\hline \multirow{6}{*}{ 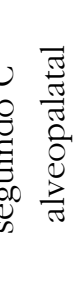 } & isto & ['iStu] & ['istu] & ['istu] & ['istu] \\
\hline & triste & ['trist & [ $t$ & 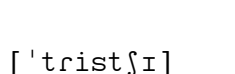 & $\tau$ \\
\hline & haste & ['aStSI] & ['astI] & ['ast $\left.\int I\right]$ & ['aStSI] \\
\hline & poste & ['poStSI] & ['postI] & [ 'post $\left.\int I\right]$ & ['postsI] \\
\hline & ginástica & [3i'naStSikə] & [3i'nastikə] & [3i'nast Sikə] & [ $3 i^{\prime}$ nastsike \\
\hline & doméstica & 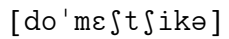 & [do'mestikə] & [do'mest Sikə] & [do'ms t t sikə] \\
\hline
\end{tabular}

Consideraremos em maiores detalhes os casos em que uma sibilante alveopalatal ocorre na variedade mineira de Belo Horizonte. Mais especificamente, investigaremos os casos em que seqüências do tipo $\left[\int t \int\right]$ ocorrem. Considere o grupo de exemplos da última coluna (variedade mineira) para o último contexto listado na coluna mais a esquerda (seguindo consoante alveopalatal). Essas seqüências estão em competição com outras seqüências alternantes. Isto é ilustrado em (12) para a palavra "ginástica".

(12) Formas alternantes da palavra ginástica
a. [3i 'nast $\left.\int i k ə\right]$ seqüência de (sibilante alveolar + africada alveopalatal) e vogal [ i]

b. [3i 'naSt Sikə] seqüência de (sibilante alveopalatal + africada alveopalatal) e vogal [ i]

c. [3i 'naSikə] seqüência de (sibilante alveopalatal) e vogal [i]

d. [3i ' na Skə] seqüência de (sibilante alveopalatal + outra consoante)

O caso ilustrado em (12d) não será tratado neste artigo. Isto porque esse caso envolve o cancelamento da vogal [i] postônica e merece um tratamento separado, pois implica a criação de uma estrutura silábica complexa: (coda + onset). Em relação aos casos (12a-c), observamos que essas três seqüências em competição ocorrem independente de a seqüência ser seguida de sílaba tônica 
ou átona. Considere as formas em (13) que são agrupadas quanto à ocorrência da seqüência em relação ao acento tônico. Os exemplos em (13) apresentam alternância entre: [st $\left.\int\right],\left[\int t \int\right]$ e [S].

(13) Distribuição de seqüências do tipo (sibilante + africada) em relação ao acento tônico

\begin{tabular}{|l|c|c|c|}
\hline \multirow{2}{*}{ Pretônica } & \multirow{2}{*}{ Tônica } & \multicolumn{2}{|c|}{ Postônica } \\
\cline { 3 - 4 } & & Postônica medial & Postônica final \\
\hline esticadinha & vestido & plástico & triste \\
\hline destilaria & estilo & ginástica & teste \\
\hline
\end{tabular}

Os exemplos em (13) mostram que a variação atestada em seqüências de (sibilante + africada) alveopalatais ocorre em sílaba tônica ou átona (pretônica e postônica). Podemos afirmar que não se aplica o condicionamento estrutural da tonicidade ao fenômeno. Ou seja, o fenômeno não parece ser condicionado pela posição da seqüência de (sibilante + africada) em relação à tonicidade. Podemos afirmar também que não há condicionamento estrutural quanto à vogal que precede essa seqüência. A consoante africada é sistematicamente seguida por [i] e não há restrição quanto à vogal que precede a sibilante posvocálica, como indicado nos exemplos que se seguem. Em (14) ilustramos casos em que qualquer uma das vogais orais do português precede a sibilante posvocálica.

$\begin{array}{ll} & \text { Vogal }+\left[\int t \int\right] \\ a & \text { ginástica } \\ \varepsilon & \text { veste } \\ e & \text { investigado } \\ i & \text { triste } \\ o & \text { poste } \\ o & \text { rostinho } \\ u & \text { rústico }\end{array}$

Se não há condicionamento estrutural que regule a redução de (sibilante + africada) alveopalatal a uma sibilante, devemos buscar elementos adicionais para que possamos compreender melhor o 
fenômeno. A nossa proposta é a de que esse fenômeno seja investigado na perspectiva da teoria da Difusão Lexical (WANG, 1969). Esse pretende ser o foco central de pesquisa futura (OLIVEIRA, em preparação). Dentro dessa abordagem, investigaremos como a variação está sendo implementada no léxico, ou seja, palavra por palavra. Como suporte adicional a essa proposta, consideraremos aspectos extralingüísticos como: idade, sexo, grau de instrução e estilo de fala. Pretendemos avaliar, ainda, o comportamento de falantes individualmente (OLIVEIRA, 1992).

A hipótese da Difusão Lexical nos parece pertinente por permitir expressar que as mudanças afetam palavras em um tempo determinado. Note que os pronomes ilustrados em (15) apresentam no português atual quase que categoricamente a forma em que somente a sibilante ocorre (sendo que a oclusiva ou a africada é cancelada). Esses pronomes são certamente muito freqüentes. A freqüência de ocorrência é possivelmente um fator que pode contribuir para a implementação de uma mudança. Contudo, o que neste momento nos interessa é que os itens em (15) se fundiram em apenas uma forma fonética em que somente a sibilante ocorre (originalmente estes exemplos tinham forma e significados diferentes).

(15) Palavras que fundiram forma e significado

$\begin{array}{lll}\text { a. este } & \text { esse } & \text { ['esI] } \\ \text { b. esta } & \text { essa } & \text { ['Esə] } \\ \text { c. isto } & \text { isso } & \text { ['isu] } \\ \text { d. neste } & \text { nesse } & \text { ['nesI] } \\ \text { e. nesta } & \text { nessa } & \text { ['nesə] } \\ \text { f. nisto } & \text { nisso } & \text { ['nisu ] } \\ \text { g. deste } & \text { desse } & \text { ['desI] } \\ \text { h. desta } & \text { dessa } & \text { ['desə] } \\ \text { i. disto } & \text { disso } & \text { ['dzisu ] }\end{array}$

Obviamente, as formas ilustradas em (15) podem apresentar a seqüência [st] em estilo formal, sobretudo em casos de leitura. $\mathrm{Na}$ fala coloquial e tipicamente em estilo informal, geralmente ocorre apenas 
a forma com a sibilante [s], como nos exemplos ilustrados em (15). Poderíamos afirmar ainda que a grande maioria dos falantes não distingue diferentes significados para os pares: este/esse, neste/nesse etc.

Consideremos um aspecto interessante que se refere aos itens (15a,d,g): este, neste, deste. Note que, se tais itens tivessem sido submetidos à mudança no estágio atual, esperaríamos ter as seguintes realizações fonéticas: [ 'e $\int \mathrm{I}$, ' $\mathrm{ne} \int \mathrm{I}, \mathrm{d} \operatorname{de} \int \mathrm{I}$ ], respectivamente para este, neste, deste. Compare, por exemplo, o comportamento da palavra leste. Em alguns dialetos que não apresentam a palatalização de oclusivas alveolares, essa palavra é pronunciada como le[st]e (com seqüência de (sibilante + oclusiva alveolar)). Em dialetos que apresentam a palatalização de oclusivas alveolares, temos as

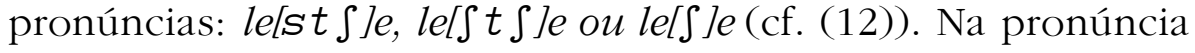
le[st $\left.\int\right] e$, a palatalização não afeta a sibilante em posição posvocálica.

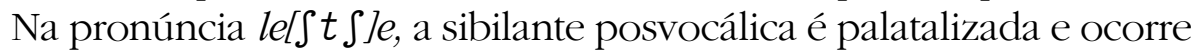
como [S]. Finalmente, na pronúncia le[S]e, a africada é cancelada e somente a sibilante ocorre.

Se compararmos o comportamento da palavra leste com o comportamento do pronome este (e também neste, deste), esperaríamos que este apresentasse as seguintes pronúncias: elst $\left.\int\right] e, e\left[\int t \int\right] e$ e $\left[\int\right] e$. De fato, em estilo formal ou de leitura, podemos atestar as formas

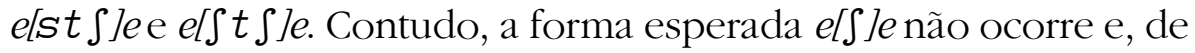
fato, temos a pronúncia els le para este. Observamos que formas estruturalmente semelhantes - lestee este-apresentam comportamentos diferentes quanto aos casos de variação em que somente a sibilante ocorre. A forma leste apresenta a pronúncia le[S]e (mas não le[s]e) e a forma este apresenta a pronúncia e[s]e (mas não el[ Je). A pronúncia diferente para seqüências estruturalmente semelhantes demonstra que o grupo de palavras em (15) deve ter sido afetado em um momento no qual a palatalização não era operante. Se a mudança estivesse relacionada ao processo de palatalização, deveríamos atestar formas que realmente não ocorrem no português contemporâneo ( $\left.\left.\left.e / \int J e, n e l \int\right] e, d e l \int\right] e\right)$.

Por outro lado, em todos os dados em (15), observamos um comportamento análogo às seqüências de (sibilantes + oclusivas) 
alveolares. Veja que, na palavra festa, que não se relaciona ao processo de palatalização de oclusivas alveolares, temos as pronúncias fe[st ]a ou fels $] a$. Note que, tanto em este quanto em festa, uma (sibilante alveolar) ocorre: $\mathrm{fe}[\mathrm{s}] \mathrm{a}$, e[s]e. Esse comportamento aparentemente inadequado pode ser facilmente capturado pela teoria da Difusão Lexical. Isto porque nesse modelo as mudanças sonoras são implementadas no léxico gradualmente. Sendo assim, a mudança sonora observada nos casos como os de (15) deve ter sido implementada numa fase diferente das palavras que têm a mesma mudança implementada neste momento (neste estágio temporal do português de Belo Horizonte, a mesma mudança seria o cancelamento da oclusiva ou africada em seqüências de (sibilante + oclusiva ou africada) sendo que somente a sibilante ocorre).

\section{CONCLUSÃO}

Este artigo teve por objetivo avaliar casos de variação sonora em seqüências de (sibilante + consoante) no português brasileiro. A ênfase foi dada às seqüências de (sibilante + oclusiva) alveolares como na palavra festa [' festa] - e às seqüências de (sibilante + africada) alveopalatais - como na palavra triste [' $\left.t r i \int t \int i\right]$. A variação que avaliamos relaciona-se aos casos em que a consoante oclusiva ou africada é cancelada e somente a sibilante ocorre: [ ' f $\varepsilon$ sa] e ['trisi].

Vimos nas seções precedentes que a motivação fonética parece contribuir para a ocorrência do fenômeno em questão, pois as consoantes envolvidas devem ter o mesmo ponto de articulação e o mesmo grau de vozeamento. Há ainda a importância de a estrutura silábica ser complexa. A hipótese básica a ser investigada em um trabalho futuro é a de que a variação envolvendo (sibilante + oclusiva) alveolares e (sibilante + africada) alveopalatais opera devido a compressão e redução de esforço articulatório, sendo que estruturas silábicas complexas tendem a ser alteradas. Essa hipótese investigará a motivação dos casos de variação que estamos analisando. 
O modelo da Difusão Lexical (WANG, 1969) permite expressar a falta de condicionamento estrutural do fenômeno. Ou seja, o fato de que nem o padrão acentual e nem a natureza da vogal que precede a seqüência segmental a ser alterada condicionam o fenômeno (cf. exemplos 13,14). A proposta da Difusão Lexical permite ainda explicarmos o comportamento distinto de seqüências segmentais estruturalmente semelhantes (cf. 15). Em uma pesquisa futura, pretendemos explorar como o modelo da Difusão Lexical permitenos explicar a implementação da mudança que estamos analisando.

A avaliação do fenômeno envolvendo seqüências de (sibilante + consoante) no português brasileiro contemporâneo apresentada neste trabalho oferece pistas iniciais de análise e indica caminhos propícios a serem explorados. Esperamos que uma visão mais completa do fenômeno possa ser oferecida. Este artigo indica aspectos a serem explorados em pesquisa futura com o objetivo de obtermos uma análise mais acurada do fenômeno em questão (OLIVEIRA, em preparação). Esperamos também que certos aspectos ainda não explorados na literatura sejam investigados. Dentre eles, destacamos os casos de aspiração de s-posvocálico (cf. $(5,6))$ e o comportamento de seqüências de (sibilantes + consoantes) em dialetos que não apresentam palatalização de oclusivas alveolares (ver nota 13). Seria relevante também investigar por que a consoante oclusiva ou africada é cancelada e não a sibilante. Vimos em $(8,9)$ que tanto a consoante que ocorre na posição de coda, quanto a consoante que segue a posição de coda podem ser canceladas. Seria importante investigar parâmetros tipológicos em relação a qual das consoantes da seqüência (coda + onset) pode ser cancelada e idealmente definir as condições que favorecem ou bloqueiam o cancelamento da consoante em questão. 


\section{NOTAS}

${ }^{1}$ Os dados são do projeto intitulado "Difusão lexical: estudo de casos do português brasileiro" (CNPq: 20.2424-86.3 e 301029-89.0).

${ }^{2}$ Seqüências de (sibilante + oclusiva) vozeadas [zd] e [3dz] são pouco freqüentes no português. Em uma pesquisa ao Dicionário Michaelis www.uol.com.br/ michaelis/, verificamos que ocorrem somente 22 palavras com a seqüência sonora [ $\mathrm{zd} 3$ ] e [3d3], em uma listagem de aproximadamente 200 mil palavras. Já as seqüências [st S] e [St S] aparecem em 2.453 palavras (dentre 200 mil). Neste artigo, restringimos a análise a estes últimos casos.

${ }^{3}$ As consoantes obstruintes compreendem as categorias de oclusivas, fricativas e africadas.

${ }^{4} \mathrm{O}$ fenômeno de enfraquecimento da sibilante em coda é verificado no português (cf. GRYNER \& MACEDO, 1981; PESSOA, 1986; RONCARATI, 1988; SCHERRE \& MACEDO, 1989 apud AULLER, 1992) e em espanhol (BYBEE, 2001). Esse tópico ainda merece uma discussão mais exaustiva no português brasileiro.

${ }^{5} \mathrm{O}$ caso de (7a) ocorre sistematicamente nas formas de gerúndio, mas pode ser observada também em outros categorias como advérbios e substantivos (MOLLICA, 1998; CRISTÓFARO-SILVA, 2000). O caso de (7b) parece ser lexicalizado. Ou seja, [g] é cancelado em pergunta, perguntado, perguntei etc., mas não em outras palavras com seqüências sonoras semelhantes: argumento, erguer, etc. Este caso merece ainda uma descrição mais detalhada.

${ }^{6}$ Sem entrarmos em detalhes, o que argumentamos aqui é que uma palavra como pergunta e semelhantes ocorre como [pehũtə] porque a seqüência sonora [ehũ] é mais recorrente do que [efigũ]. Por outro lado, em palavras como argumento, erguer, etc., a seqüência [ahũ] e [ehe]é menos recorrente do que [afigu] e [ehige].

${ }^{7}$ A indicação das variedades dialetais tem caráter de agrupar variedades com os traços descritos: distribuição das sibilantes posvocálicas. Na variedade paulista, nos referimos às comunidades que não apresentam a propriedade de palatalização de oclusivas alveolares.

${ }^{8}$ Excluímos as vogais nasais e ditongos dos exemplos em (14) por serem menos recorrentes em português do que as vogais orais. Contudo, note que há exemplos que ilustram a ocorrência de vogais nasais seguidas da seqüência [ $\left.\int t \int\right]$ : 'in[ $\int t \int$ ]ituição' ou 'con[ $\left.\int t \int\right]$ lituição'. Ditongos decrescentes raramente ocorrem seguidos da seqüência [ $\int \mathrm{t} \int$ ]. Tipicamente, há restrições quanto à ocorrência de ditongos decrescentes seguidos de consoantes posvocálicas, como em cáustica, exaustivo, etc. 
9 No corpus do projeto "Difusão Lexical: estudo de casos do português brasileiro" que conta com 47.883 palavras, na fala espontânea, foram constatadas apenas cinco ocorrências do pronome isto e uma ocorrência do pronome disto. Essas formas foram pronunciadas por membros da mesma família. Os demais pronomes demonstrativos apareceram apenas com a forma em que somente a sibilante alveolar [s] ocorre.

${ }^{10}$ Seria interessante avaliar se em dialetos que não-palatalizam as oclusivas alveolares a pronúncia le[s]e ocorre. Não possuímos dados neste estágio da pesquisa quanto a essa pronúncia

\section{REFERÊNCIAS BIBLIOGRÁFICAS}

AUllER, M. A difusão lexical de um fenômeno de aspiração no português. Revista de Estudos da Linguagem, Belo Horizonte, v. 1, ano 1, 1992.

BARRY, W.; ANDREVA, B. Cross-languages similarities and differences in spontaneous speech patterns. Journal of the International Phonetic Association, v. 31, n.1, p. 51-66. CUP, 2001.

BROWMAN, C.; GOLDSTEIN, L. Articulatory Phonology: An overview. Phonetica 49, p.155-180, 1992.

BYBEE, J. Frequency and the emergency of linguistic structure. Amsterdan: Philadelphia, PA: John Bejamins Publish, 2001.

CRISTÓFARO-SILVA, T. Sobre a Quebra de Encontros Consonantais no Português Brasileiro. Estudos Lingüísticos. São Paulo, v. 29, p 522-527, 2000.

CRISTÓFARO-SILVA, T. Fonética e fonologia do português: roteiro de estudos e guia de exercícios. São Paulo: Contexto. 2001a.

CRISTÓFARO-SILVA, T. Difusão Lexical: Estudo de casos do português brasileiro. In: MENDES, E. A. de M., OLIVEIRA, P. M.; BENN-IBLER, V. (Org.). O novo milênio: interfaces lingüisticas e literárias . Belo Horizonte: UFMG/FALE. p. 209-218, 2001b.

CRISTÓFARO-SILVA, T. Difusão lexical: estudo de casos do português brasileiro. Relatório final de Pesquisa. (em preparação).

GOLDsmith, J. Autosegmental and Metrical Phonology. Oxford: Basil \& Blackwell, 1990.

GRYNER, H.; MACEDO, A. La prononciation du s post-vocalique deux processus de changement linguistique en portugais. In: Variation omnibus. Canada, Linguistique Research, p. 135-140, 1981. 
MATTOSO CÂMARA JR., J. Estrutura da língua portuguesa. 14. ed. Petrópolis, RJ: Vozes, 1970.

MICHAELIS - Moderno Dicionário da Língua Portuguesa. Edições Melhoramentos. Disponível em: www.uol.com.br/michaelis/, 2002.

MOLLICA, M. C. Influência da fala na alfabetização. Rio de Janeiro: Tempo Brasileiro, 1998.

OLIVEIRA, M. A. Reanálise de um problema de variação. In: Português: Estudos lingüísticos, Série Estudos, v.7, FISTA, 23-51, 1981.

OlIVEIRA, M. A. Aspectos da difusão lexical. Revista de Estudos da Linguagem, Belo Horizonte, v. 1, p. 31-41, 1992.

OLIVEIRA, M. A. Reanalisando o processo de cancelamento do (r) em final de sílaba. Revista de Estudos da Linguagem. Belo Horizonte, v. 6, n. 2, 1999.

OLIVEIRA, Daniela Mara Lima. Seqüências de (sibilante +africada alveopalatal) no português de Belo Horizonte. Projeto de mestrado (em preparação).

PESSOA, M. A. F. C. Um processo de enfraquecimento na fonologia do português. Monografia apresentada no curso de Doutorado em Lingüística da Faculdade de Letras da UFRJ, 1986.

RONCARATI, C. N. S. Enfraquecimento das fricativas sonoras. In: Relatório final à FINEP - Projeto Dialetos Sociais Cearenses. Fortaleza Universidade Federal do Ceará. Convênio FINEP; CCPC 41.85.0655.00, 1988.

SCHERRE, M. M. P.; MACEDO, A. T. Variação e mudança: o caso da pronúncia do S-posvocálico. In: Relatório final à FINEP - Projeto: Mecanismos Funcionais do uso Lingüístico. Rio de Janeiro. UFRJ. Convênio FINEP-UFRJ, 1989.

WANG, W. S-Y. Competing changes as a cause of residue. Language, n. 45, 1969. 